University of Nebraska - Lincoln

DigitalCommons@University of Nebraska - Lincoln

Biological Systems Engineering: Papers and

Publications

Biological Systems Engineering

2008

\title{
Visible/Near-Infrared Hyperspectral Imaging for Beef Tenderness Prediction
}

\author{
Govindarajan Konda Naganathan \\ University of Nebraska-Lincoln, gkondanaganathan2@unl.edu \\ Lauren M. Grimes \\ University of Nebraska-Lincoln \\ Jeyamkondan Subbiah \\ University of Nebraska-Lincoln, jeyam.subbiah@unl.edu \\ Chris R. Calkins \\ University of Nebraska-Lincoln, ccalkins1@unl.edu \\ Ashok Samal \\ University of Nebraska-Lincoln, asamal1@unl.edu \\ See next page for additional authors
}

Follow this and additional works at: https://digitalcommons.unl.edu/biosysengfacpub

Part of the Biological Engineering Commons

Naganathan, Govindarajan Konda; Grimes, Lauren M.; Subbiah, Jeyamkondan; Calkins, Chris R.; Samal, Ashok; and Meyer, George E., "Visible/Near-Infrared Hyperspectral Imaging for Beef Tenderness Prediction" (2008). Biological Systems Engineering: Papers and Publications. 178.

https://digitalcommons.unl.edu/biosysengfacpub/178

This Article is brought to you for free and open access by the Biological Systems Engineering at DigitalCommons@University of Nebraska - Lincoln. It has been accepted for inclusion in Biological Systems Engineering: Papers and Publications by an authorized administrator of DigitalCommons@University of Nebraska Lincoln. 


\section{Authors}

Govindarajan Konda Naganathan, Lauren M. Grimes, Jeyamkondan Subbiah, Chris R. Calkins, Ashok Samal, and George E. Meyer 
Published in Computers and Electronics in Agriculture 64 (2008): 225-233; doi: 10.1016/j.compag.2008.05.020

Copyright (C) 2008 Elsevier Ltd. Used by permission.

http://www.sciencedirect.comjournalhomepage:www.elsevier.com/locate/compag

Submitted September 19, 2007; revised May 8, 2008; accepted May 14, 2008;

posted in the University of Nebraska-Lincoln Digital Commons October 2010.

\title{
Visible/Near-Infrared Hyperspectral Imaging for Beef Tenderness Prediction
}

\author{
Govindarajan Konda Naganathan, ${ }^{1}$ Lauren M. Grimes, ${ }^{2}$ Jeyamkondan Subbiah, ${ }^{1}$ \\ Chris R. Calkins, ${ }^{2}$ Ashok Samal, ${ }^{3}$ and George E. Meyer ${ }^{1}$
}

1. Biological Systems Engineering, University of Nebraska-Lincoln, Lincoln, NE, USA

2. Animal Science, University of Nebraska-Lincoln, Lincoln, NE, USA

3. Computer Science and Engineering, University of Nebraska-Lincoln, Lincoln, NE, USA

Corresponding author - J. Subbiah, email jsubbiah2@unl.edu

\begin{abstract}
Beef tenderness is an important quality attribute for consumer satisfaction. The current beef quality grading system does not incorporate a direct measure of tenderness because there is currently no accurate, rapid, nondestructive method for predicting tenderness available to the beef industry. The objective of this study was to develop and test a visible/nearinfrared hyperspectral imaging system to predict tenderness of 14-day aged, cooked beef from hyperspectral images of fresh ribeye steaks acquired at 14-day post-mortem. A push-broom hyperspectral imaging system (wavelength range: 400-1000 nm) with a diffuse-flood lighting system was developed and calibrated. Hyperspectral images of beef-steak $(n=111)$ at 14 -day post-mortem were acquired. After imaging, steaks were cooked and slice shear force (SSF) values were collected as a tenderness reference. All images were corrected for reflectance. After reflectance calibration, a region-of-interest (ROI) of $200 \times 600$ pixels at the center was selected and principal component analysis was carried out on the ROI images to reduce the dimension along the spectral axis. The first five principal components explained over $90 \%$ of the variance of all spectral bands in the image. Gray-level textural co-occurrence matrix analysis was conducted to extract second-order statistical textural features from the principal component images. These features were then used in a canonical discriminant model to predict three beef tenderness categories, namely tender (SSF $\leq 205.80 \mathrm{~N}$ ), intermediate $(205.80 \mathrm{~N}<$ SSF $<254.80 \mathrm{~N})$, and tough $(\mathrm{SSF} \geq 254.80 \mathrm{~N})$. With a leave-one-out cross-validation procedure, the model predicted the three tenderness categories with a $96.4 \%$ accuracy. All of the tough samples were correctly identified. Our results indicate that hyperspectral imaging has considerable promise for predicting beef tenderness.
\end{abstract}

Keywords: beef tenderness, hyperspectral imaging, principal component analysis, textural co-occurrence matrices, instrument grading

\section{Introduction}

The United States beef industry is a significant part of the nation's food and fiber industry. To facilitate marketing, beef grading standards to classify carcasses into quality and yield grades were developed in 1926 by the United States Department of Agriculture (USDA). There are commercial video image analysis-based systems available to assist the prediction of yield grades. But quality grades based on marbling levels (abundance and distribution of intramuscular fat) and phys- 

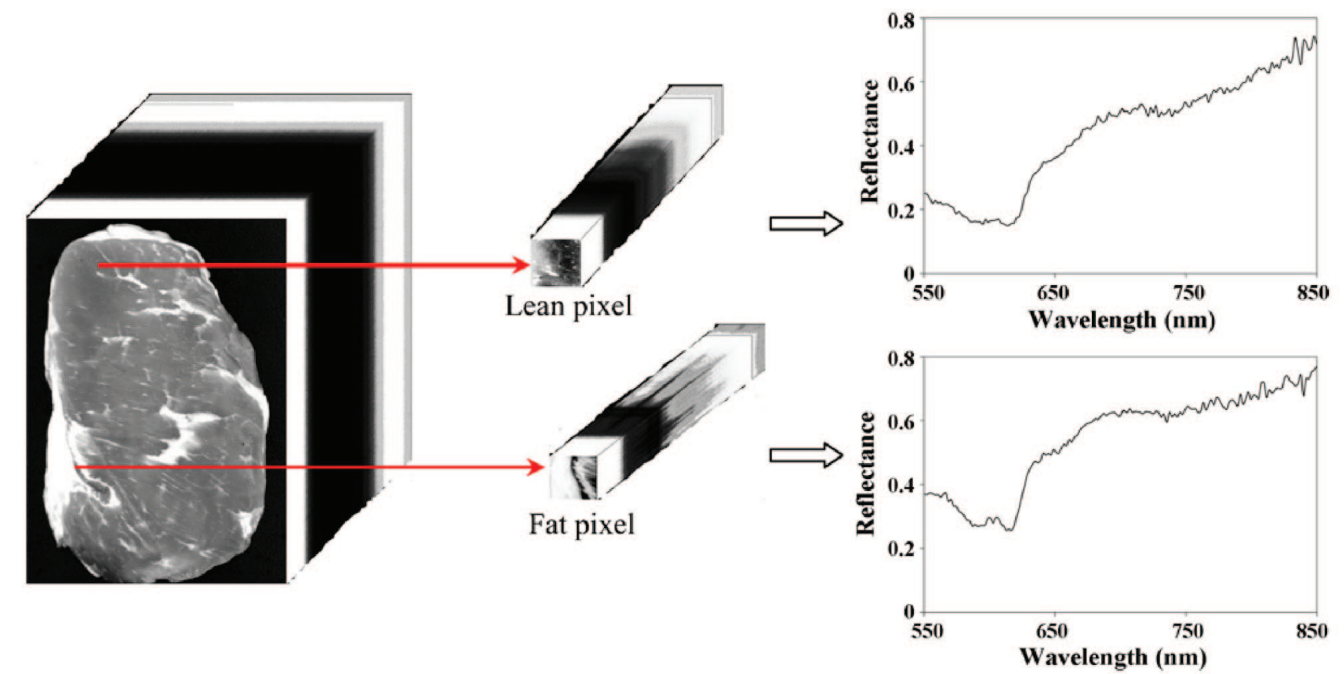

Figure 1. A hyperspectral image of a beef-steak showing typical spectral signatures of lean and fat pixels.

iological maturity of the carcass are subjectively (visual appraisal) assigned by trained USDA graders. Food service providers in the U.S. receive $95 \%$ of their beef products from the "A" maturity carcass grade (NAMP, 2007). Therefore, the current grading system is based primarily on the degree of marbling.

Tenderness, juiciness, and flavor of beef are important attributes of palatability (Shackelford et al., 2001). Among these three attributes, tenderness is the single, most important palatability attribute for U.S. consumers. Several studies (Boleman et al., 1997; Lusk et al., 2001; Shackelford et al., 2001; Feuz et al., 2004) have shown that most consumers can discriminate levels of tenderness. Most consumers are willing to pay a premium for steaks that are "guaranteed tender." Marbling is highly indicative of juiciness and flavor but only slightly related to tenderness (Jeremiah, 1996; Wheeler et al., 1994). Thus, the current USDA quality grading system may not always categorize carcasses correctly based on tenderness, one of the most important palatability attributes for consumer satisfaction.

The National Beef Quality Audits (Lorenzen et al., 1993), 1995 (Boleman et al., 1998), and 2000 (McKenna et al., 2002) and National Beef Tenderness Surveys conducted in 1991 (Morgan et al., 1991) and 1998 (Brooks et al., 2000) identified the lack of tenderness as a major concern for the beef industry. Currently, the USDA grading system does not include a direct measure of tenderness. Carcasses are not priced on the basis of tenderness, so producers lack incentive to supply a tender product. As a result, consumer preference is not usually considered by producers. An accurate, rapid, and nondestructive method for predicting tenderness is needed by the beef industry.

Of the various noninvasive beef tenderness prediction techniques, video image analysis (VIA) and spectroscopy are potential methods for on-line implementation (Shackelford et al., 1999; Vote et al., 2003). A color VIA system can capture images in three distinct wavelengths or bands (RGB: red-greenblue). Modern digital RGB images can have a high spatial resolution, but have a limited spectral resolution. A spectrometer provides high spectral resolution information over both visible and near-infrared spectral regions but with virtually no spatial information. Zheng et al. (2006) used VIA and discriminant models to classify beef samples into two categoriestender and tough. They used textural features and achieved a prediction accuracy of $70.3 \%$.

Mitsumoto et al. (1991) pioneered the use of spectroscopy for beef tenderness prediction and obtained an accuracy of $68 \%$ in predicting tenderness. Subsequently several additional studies reported moderate to promising results in predicting beef tenderness (Hildrum et al., 1994, 1995; Rødbotten et al., 2001; Park et al., 1998; Jeyamkondan and Kranzler, 2003; Liu et al., 2003). However, contradictory results have been reported in the literature regarding the use of spectroscopy for beef tenderness prediction. Orientation of the sample with respect to light and various chemometric data analysis methods were the major reasons for contradictory results. Recently, Xia et al. (2006) measured spatially resolved light scattering and absorption of beef samples between 450 and $950 \mathrm{~nm}$ using a fiber optic probe. They reported that absorption and scattering coefficients have direct relationships with chemical composition (myoglobin concentration) and structural properties (sarcomere length), respectively. They found a linear relationship between the scattering coefficient and Warner-Bratzler shear values with a $R^{2}$ of 0.59 .

A hyperspectral imaging system, which consists of both a digital camera and a spectrograph, can acquire images with both high spatial and spectral resolution content. Therefore, this system could be considered an extension of a VIA system with hundreds of narrow spectral bands along the spectral axis. With hyperspectral imaging, a spectrum for each pixel can be obtained (Figure 1) and a gray scale or tonal image for each narrow band (Figure 2) can be obtained. Hyperspectral imaging has been successfully tested for several precision agricultural applications (Bajwa et al., 2004) and food quality/ safety areas (Kim et al., 2001). Hyperspectral imaging systems have been used to detect fecal contamination in apples (Kim et al., 2002a), skin tumors in chicken carcasses (Kim et al., 2002b), feces on the surface of poultry carcasses (Park et al., 2002, 2004, 2005a,b), and cucumber chilling damage (Cheng et al., 2004).

Muscle structure (connective tissue) and biochemical properties (proteolysis of myofibrillar and cytoskeletal proteins) 


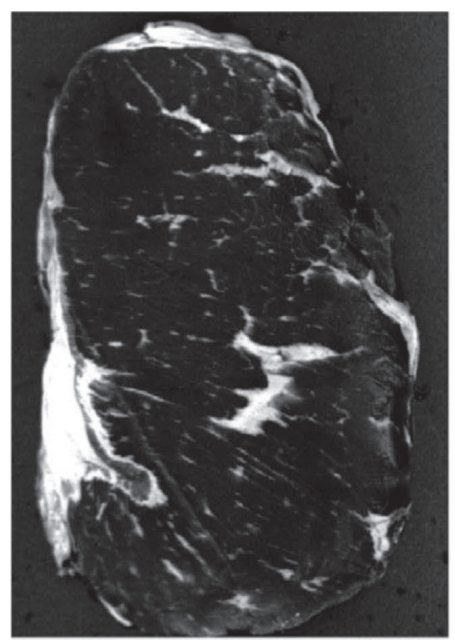

@ 600 nm

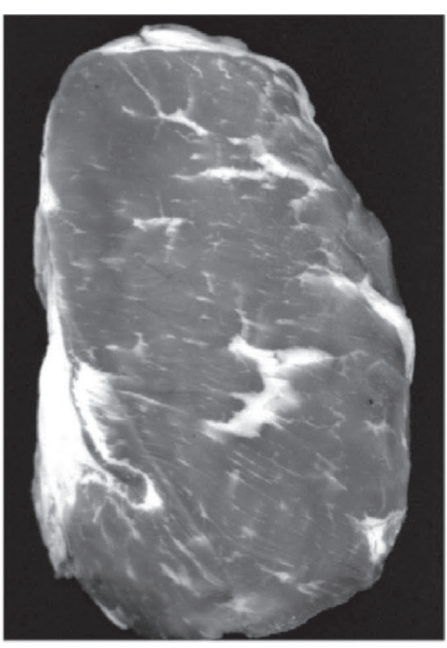

$@ 700$ nm

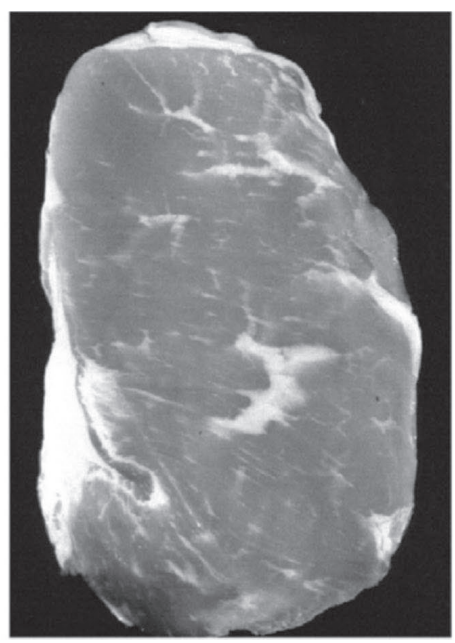

@ $800 \mathrm{~nm}$

Figure 2. Tonal images of a beef-steak at selected wavelengths.

are the primary factors influencing beef tenderness variation (Koohmaraie, 1994). VIA systems were used to relate image textural features to beef muscle structure (Zheng et al., 2006; Du and Sun, 2006), while spectroscopic systems were used to relate spectral reflectance measurements to chemical composition of beef (Park et al., 2001; Hildrum et al., 1994). VIA and spectroscopy are two promising nondestructive methods, but have achieved only limited success for predicting beef tenderness. This study explores a relatively new technique for beef tenderness prediction using hyperspectral imaging, which combines VIA and spectroscopy. Hyperspectral imaging may capture both structural and biochemical information simultaneously so that the likelihood of predicting beef tenderness accurately could be much greater. The overall objective of this study was to predict 14-day aged, cooked beef tenderness from hyperspectral images of 14-day aged, raw beef samples.

\section{Materials and methods}

\subsection{Hyperspectral imaging system}

A hyperspectral imaging system (Figure 3) consisting of a charge coupled device (CCD)-based digital video camera (Model: IPX2M30, Imperx Inc., Boca Raton, FL) and a spectrograph (Model: Enhanced series Imspector V10E, Specim, Finland) was used. The Imperx camera has a spatial resolution of $1600 \times 1200$ pixels. The image was binned $2 \times 4$ vertically to improve the signal/noise ratio, which resulted in a final resolution of $800 \times 300$ after binning. The spectrograph, V10E, had a spectral range of $400-1000 \mathrm{~nm}$, with a $30-\mathrm{m}$ slit, providing a spectral band resolution of $2.8 \mathrm{~nm}$. The camera was fitted with a $12.5 \mathrm{~mm}$ lens. The system scans a single-spatial line of a target object, and the spectrograph disperses light from each line element or pixel to a spectrum. Thus, each spectral image contains lines of pixels in one axis (800 pixels) and spectral pixels in the other axis (300 pixels). To obtain a three-dimensional (3D) hyperspectral data cube, the object has to be scanned or moved along a second spatial dimension. A linear motorized slide (Model: MN10-0300, Velmex Inc., Bloomfield, NY) was used to move the sample using a stepper motor (Model: MDrive23, Intelligent Motion Systems, Glastonbury, CT). The stepper motor was controlled by the computer via a serial port so that both camera scanning and slide motion could be synchronized. A scanning rate was selected to achieve a square pixel. A Teflon-coated plate was mounted on the linear slide. The sample was placed on the slide along with a white reference Spectralon plate (Labsphere, North Sutton, NH). This Teflon-coated plate was mounted on the linear slide.

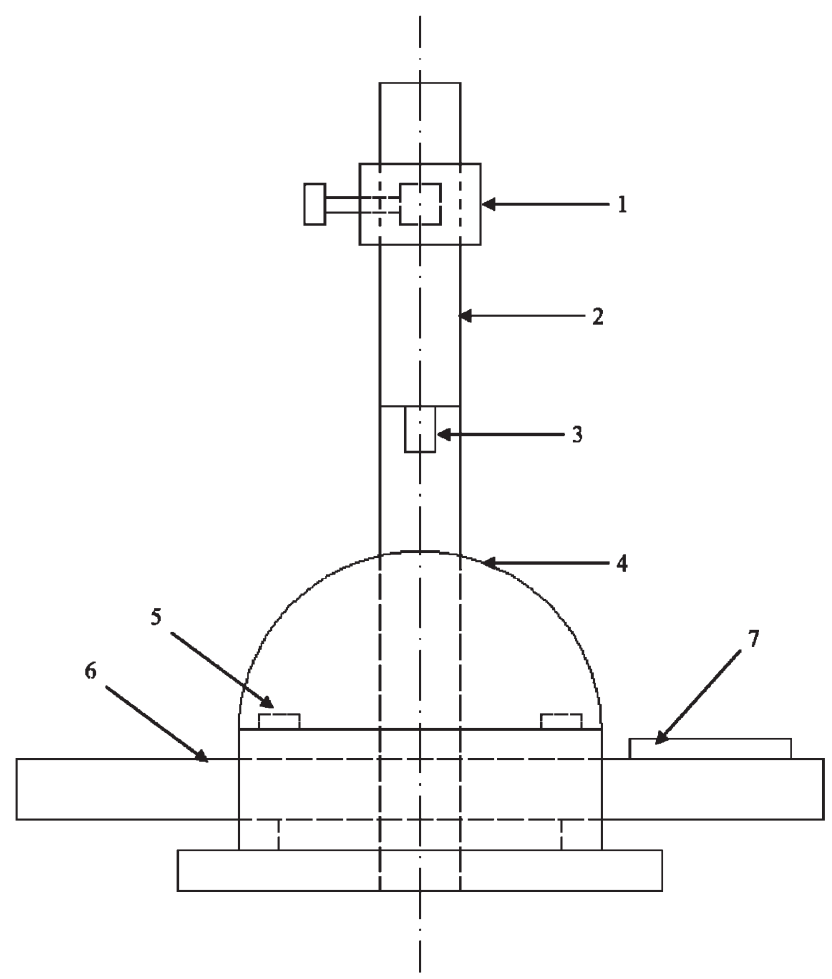

[1] CCD camera. [2] Spectrograph. [3] Lens. [4] Diffuse lighting chamber. [5] Tungsten halogen lamps. [6] Linear slide. [7] Sample plate.

Figure 3. Schematic diagram of the visible near-infrared hyperspectral imaging system. 
A diffuse lighting chamber was designed to illuminate the target. Lighting was provided with six 50-W tungsten-halogen lamps (Model: MR16, Phillips Lighting Co.). A lamp controller (Model: TXC300-72/120, Mercron Industries, Richardson, TX) converted $60-\mathrm{Hz}$ AC voltage to $60-\mathrm{kHz}$. At this high frequency, tungsten-halogen lamps do not respond quickly. This simulated a constant DC voltage power supply. Over the lifespan, tungsten-halogen lamps lose their efficiency and produce less light output. A photodiode was placed near a tungsten-halogen lamp to provide feedback to the controller. Based on this feedback, the current input to the tungsten-halogen lamps was increased over the life of the lamp to provide a constant intensity output. A hemispherical dome of $40-\mathrm{cm}$ diameter was placed over the lamps. The inner surface of the dome was painted with white paint (Munsell white reflectance coating, Edmund Optics, Barrington, NJ). The reflective dome provided uniform diffuse light over the steak. The hyperspectral camera was placed on a rack and pinion arrangement on a video mounting workstation (Edmund Optics) to alter working distance. The camera acquired the image of a steak through a viewport in the top of the hemispherical dome.

\subsection{Calibration of the hyperspectral imaging system}

A pushbroom hyperspectral imaging system was used to scan lines of an object and disperse them into a two-dimensional (2D) image, where the horizontal and vertical dimensions corresponded to spatial and spectral axes, respectively. The object has to be moved at a controlled speed to get the full image of the object. This working nature of the imaging system makes the job of ensuring proper focus and determining pixel size difficult. Therefore, the system needs to be calibrated. A target with parallel straight lines of known length was placed on the sample plate and the working distance and focus of the camera was adjusted until the camera produced a sharp image, in which the lines were straight and parallel to each other. Pixel size was calculated by counting the number of pixels covering a known distance in the image.

Mercury Argon (Model: Newport 6035) and Krypton (Model: Newport 6031) calibration lamps, which provide unique peaks at particular wavelengths between 400 and $1000 \mathrm{~nm}$, were used for spectral calibration. The procedure explained by Lawrence et al. (2003) was followed to develop a regression equation to convert band numbers to wavelengths.

\subsection{Steak Samples}

Beef ribeye steaks (longissimus dorsi muscle) between the 12th and 13th ribs were collected from four different regional packing plants and were aged for 14 days in vacuum packages. After aging, the steaks $(n=111)$ were frozen and shipped to a central location. Before imaging, the samples were thawed overnight at refrigerated temperatures in a cooler. As the samples for this study were randomly collected from four different regional packing plants on different days, freezing was the only way of controlling age of the samples. It is very important to have samples with the same age, because age has direct relationship with tenderness. Each individual steak sample was vacuum packaged and frozen quickly. Then, the sam- ples were thawed slowly at refrigerated temperatures to minimize changes in texture or muscle structure. During the freezing and thawing process, the characteristics of the samples may change. However, this process was applied to all samples in a consistent manner and should produce uniform changes in the characteristics of the samples. Therefore, this uniform change in the sample characteristics would have minimal effect on tenderness variation between samples, and the ability of a system to discriminate samples based on tenderness. This is a "proof-of-concept" study to demonstrate the effectiveness of hyperspectral imaging to predict beef tenderness. Eventually, this study has to be repeated on unfrozen samples before industrial implementation.

Steaks were removed from the vacuum packages and were allowed to oxygenate for $30 \mathrm{~min}$. After imaging, the steaks were cooked in an impingement oven with a moving-belt. Slice shear force (SSF) values were measured and recorded following the procedures presented by Shackelford et al. (2001). Based on the SSF values, the samples were classified into three tenderness categories: tender $(\mathrm{SSF}=205.80 \mathrm{~N})$, intermediate $(205.80 \mathrm{~N}<\mathrm{SSF}<254.80 \mathrm{~N})$, and tough $(\mathrm{SSF}=254.80 \mathrm{~N})$. The SSF cutoff values used to classify beef samples into three tenderness categories were selected as per the U.S. beef industry practice (Personal communication with Dr. Daniel Schaefer, Director, Research and Development, Cargill Meat Solutions, KS). These categories were used as the references for canonical discriminant model development.

\subsection{Image Processing}

The hyperspectral image files were then exported to Environment for Visualizing Images (ENVI) software (Research Systems Inc., Boulder, CO) for further image processing and analysis.

\subsubsection{Reflectance calibration}

The calibration process included corrections for dark current and sensor response variation due to time and temperature. During image acquisition, dark current estimates were obtained at regular intervals and it was subtracted pixel-bypixel from the steak image. Also, a 99\% white reference plate was placed near the samples and used for reflectance correction. By thresholding, a portion of the white reference plate in image was segmented. The spectrum of each pixel in the image was then divided by the average spectrum of the white reference to calculate the reflectance image. By calculating reflectance, differences due to illumination from one sample to another sample were minimized or eliminated.

\subsubsection{Principal component analysis}

After calculating reflectance, a region-of-interest (ROI) of size $200 \times 600$ pixels $(37.5 \mathrm{~mm} \times 112.5 \mathrm{~mm})$ at the center of the image was selected. The image center coordinates were first derived, and the ROI was selected with respect to the image center coordinates. No manual interaction was required to select the ROI. The ROI size was selected in such a way that the ROI fit within the ribeye area. Principal component analysis (PCA) was performed on the ROI images to reduce the dimension along the spectral axis. Further image processing steps were implemented on the principal component $(\mathrm{PC})$ images. 


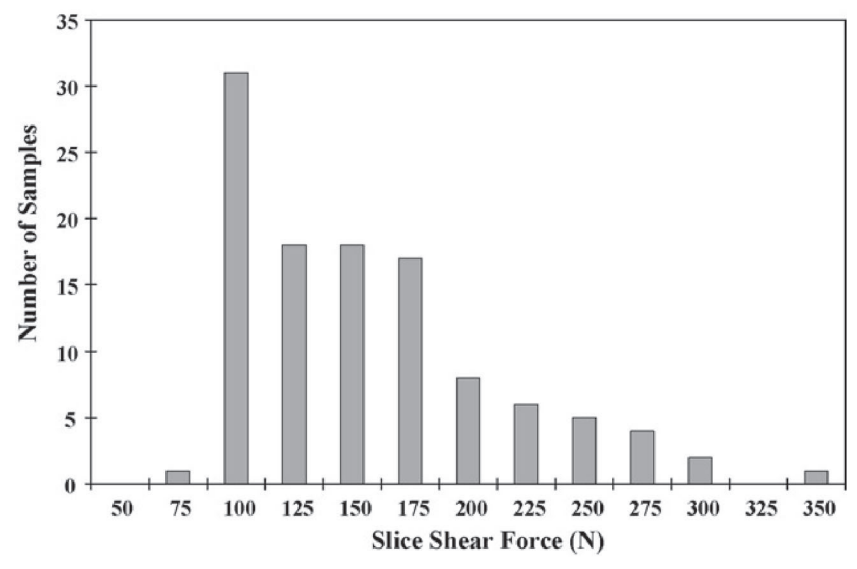

Figure 4. Sample distribution of longissimus dorsi muscle based on slice shear force (SSF) measurement.

\subsubsection{Gray-level co-occurrence matrix analysis}

On the PC images, four gray-level co-occurrence matrix (GLCM) analyses with a distance value of 1 and angles of $0^{\circ}$, $45^{\circ}, 90^{\circ}$, and $135^{\circ}$ were constructed for extracting image textural features. The $g$ level was set as 64 to reduce computation time. The GLCM procedure was used to obtain eight textural feature images or bands: mean, variance, homogeneity, contrast, dissimilarity, entropy, second moment, and correlation (Haralick et al., 1973). The mean values of textural images or bands were calculated for each textural band, giving 40 textural features for each original beef image.

\subsection{Canonical discriminant model development}

Canonical discriminant analysis (CDA) is a statistical dimensionality reduction and classification technique, and creates special canonical variables or scores, which are a linear combination of all feature variables. Using canonical scores for each observation, the CDA procedure calculates a membership value for each observation and assigns observation into classes (Johnson, 1998).

The canonical discriminant algorithm was developed in SAS 9.1 (The SAS Institute, Cary, NC). The 40 extracted textural features from each image and the tenderness categories defined based on the SSF values were used as independent and dependent variables, respectively, in developing a canonical discriminant model. An option to conduct a hypothesis test for using pooled covariance matrix or within class covariance matrices was selected.

\section{Results}

Hyperspectral images $(n=111)$ of USDA Choice and Select beef longissimus steaks (14 day post-mortem) were collected in less than $10 \mathrm{~s}$ per sample. However, the computer processing time required to assign a tenderness category was approximately 10 min per sample (Intel Xeon Dual Core computer with 3-GHz processor and 4-GB RAM). The reference tenderness values or SSF values ranged from 72.86 to $329.91 \mathrm{~N}$ with a mean and standard deviation of 143.62 and $55.64 \mathrm{~N}$, respectively (Figure 4).
Figure 5 shows a typical hyperspectral image textural feature extraction procedure. The original image had 300 tonal bands (Figure 5a). Due to a low signal to noise ratio, 75 bands at each extreme of the spectral range were excluded from the analysis. Therefore, 150 bands in the middle spectral region, representing a wavelength range between 550 and $850 \mathrm{~nm}$, were used. All images were corrected for reflectance (Figure $5 b$ ) to minimize variations due to sensor response, illumination, and temperature. The ROI image was obtained (Figure 5c).

PCA was then implemented to reduce the spectral dimension of the ROI hyperspectral image. The optimal number of PC images was chosen with Eigen values significantly greater than zero (Johnson, 1998). For this step, the first five PC images had Eigen values significantly greater than zero. These Eigen values (Figure 5d-h) explained over $90 \%$ of the variance of all bands for the image.

In this study, a non-traditional PCA approach was followed. Each hyperspectral image was considered as a separate data set and PCA was conducted for each image separately to retain spatial variability of samples, instead of mosaicking all images. The loading vectors or Eigen vectors are different among images. This approach explains 'within sample' variation. Furthermore, the wavelengths 568, 590, 604, 614, 636, 722, 736, and $814 \mathrm{~nm}$ (Figure 6) played major roles in constructing the PC images. In PC image 1 (Figure $5 \mathrm{~d}$ ), fat pixels are brighter than lean pixels; where as in PC images 3 (Figure 5f) and 4 (Figure $5 \mathrm{~g}$ ), lean pixels are brighter than fat pixels. Such significant contrast differences could be used for segmenting lean and fat regions and calculating a marbling score.

GLCM was used to extract textural features from PC images. The second-order textural feature extraction routine produced textural tonal images (Figure 5i-p), mean, variance, homogeneity, contrast, dissimilarity, entropy, second moment, and correlation. The average value of each textural band was then calculated and used in developing a canonical discriminant model to classify steaks into three tenderness categories: tender, intermediate and tough. Figure 7 shows the distribution of samples in this canonical space. The hypothesis test for using pooled covariance matrix was accepted. This plot shows considerable clustering of the tenderness categories, with minimal overlap.

Therefore, a linear discriminant function was employed in forming the classification rules. Using a leave-one-out crossvalidation procedure, 93 of the 94 tender samples were correctly classified, one was misclassified as intermediate and no tender sample was misclassified as tough. Of the 12 intermediate samples, nine were accurately classified as intermediate, three were misclassified as tender and no intermediate sample was misclassified as tough. All five tough samples were correctly identified. Out of 111 samples, the number of tender, intermediate, and tough samples was 94 (84.7\%), 12 (10.8\%) and $5(4.5 \%)$, respectively. Overall accuracy was $96.4 \%$ (Table 1 ). This suggests that this classification method has some potential in predicting beef tenderness.

\section{Discussion}

Inconsistency in beef tenderness is a major problem faced by the beef industry. Even an occasional unsatisfactory experience due to the consumption of a tough steak can significantly 


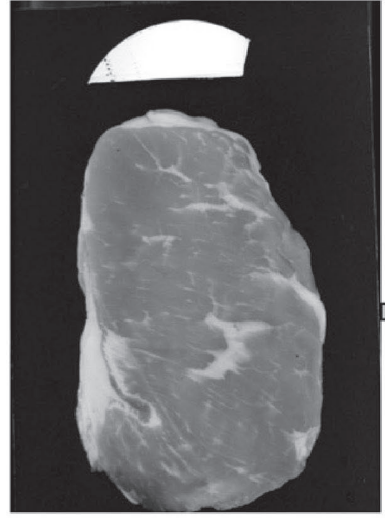

[a]

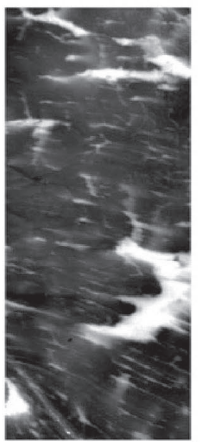

[d]

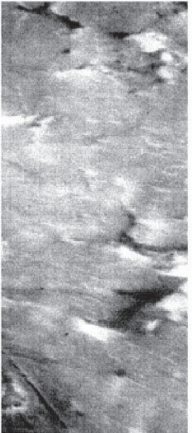

[e]

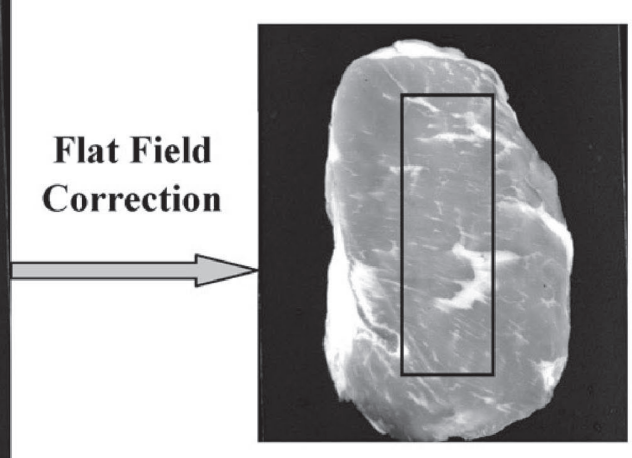

[b]

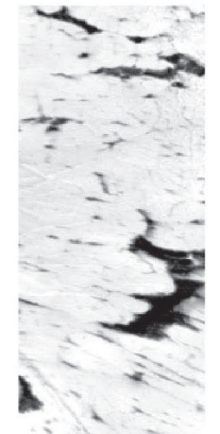

[f]

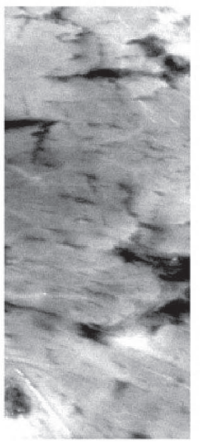

[g]

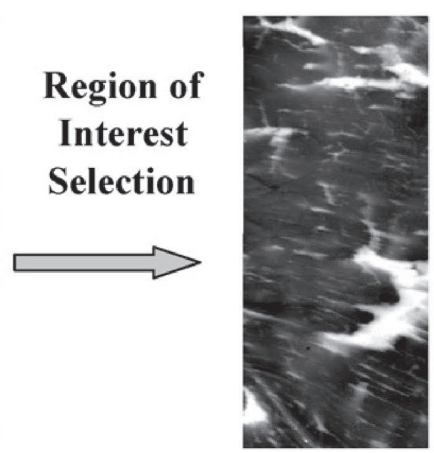

[c]

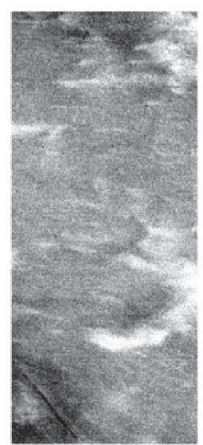

[h]

Gray-Level Co-occurrence Matrix Analysis (GLCM)
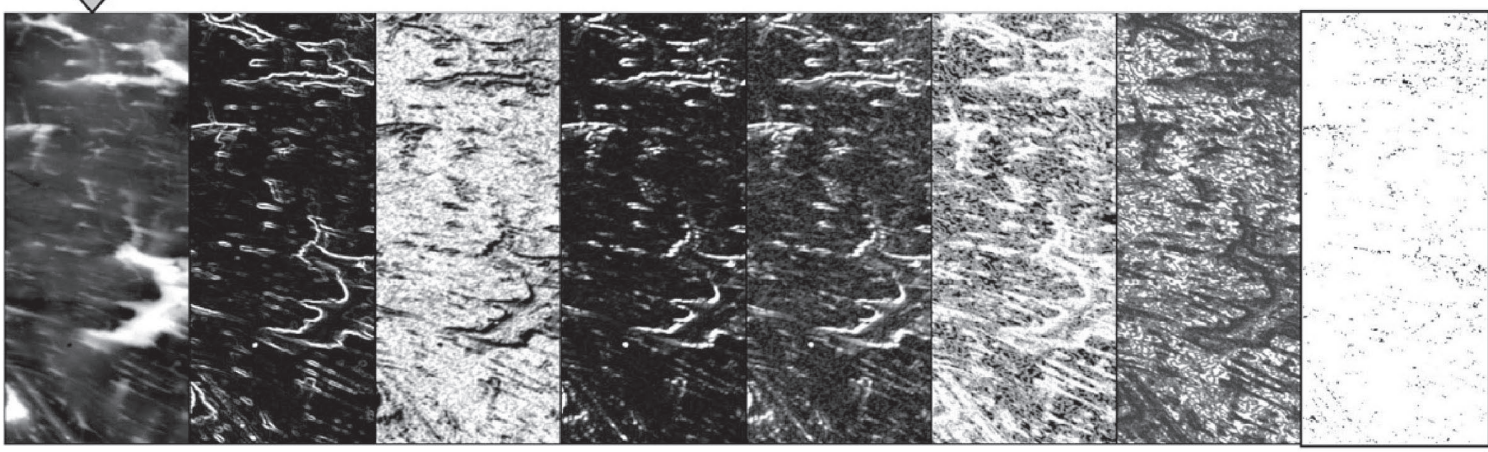

[i]

[j]

$[\mathrm{k}]$

$[1]$

$[\mathrm{m}]$

[n]

[o]

[p]

[a]. Uncalibrated Image [b]. Calibrated Image [c]. Region of Interest Image $[\mathrm{d}-\mathrm{h}]$.Principal Component Images 1 through $5[\mathrm{i}-\mathrm{p}]$. Textural Images [i]. Mean [j]. Variance [k]. Homogeneity [1]. Contrast [m]. Dissimilarity [n]. Entropy [o]. Second Moment [p]. Correlation

Figure 5. Hyperspectral image textural feature extraction methodology.

influence the consumer's future buying. The beef industry is looking for a noninvasive instrument to predict beef tenderness from fresh steaks. Tenderness is a property of a cooked product and predicting that property from a fresh steak poses considerable challenges. In this study, an innovative technique, hyperspectral imaging, capable of collecting spectral in- formation at each and every pixel of the image has been developed and tested.

The samples used in this study were collected randomly from a commercial branded beef program, which aims to produce only tender samples. Therefore, the number of intermediate and tough samples was less. McKenna et al., 2002 
reported that about $90 \%$ of the carcasses have only two quality grades namely USDA Choice and Select. Because we randomly collected samples from a normal population - typically found in a packing plant, all our samples represent only two of the seven USDA quality grades. These two quality grades exemplify only four marbling levels out of eleven. Despite the narrow range of samples used for testing this system, the accuracy was over $96 \%$ that shows considerable promise for this technique for beef tenderness prediction.

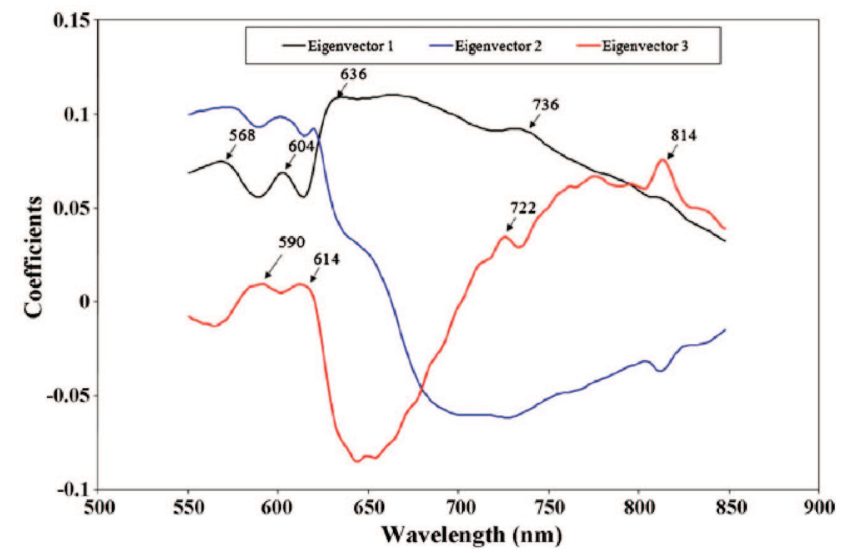

Figure 6. First three loading or Eigen vectors of principal component analysis (PCA).

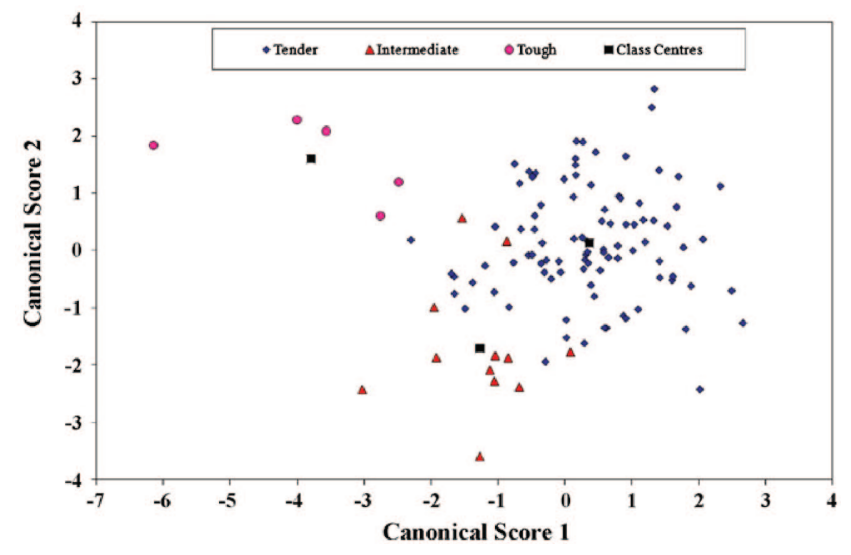

Figure 7. Distribution of samples in the canonical space.

Table 1. Beef-steak classification using leave-one-out crossvalidation and a canonical discriminant model

\begin{tabular}{lcccc} 
Actual categories $^{\mathrm{a}}$ & \multicolumn{3}{c}{ Predicted categories } & \multirow{2}{*}{ Total } \\
\cline { 2 - 3 } & Tender & Intermediate & Tough & \\
\hline Tender $^{\mathrm{b}}$ & 93 & 1 & 0 & 94 \\
Intermediate $^{\mathrm{c}}$ & 3 & 9 & 0 & 12 \\
Tough $^{\mathrm{d}}$ & 0 & 0 & 5 & 5 \\
Total & 96 & 10 & 5 & 111 \\
\hline
\end{tabular}

a Defined based on slice shear force (SSF).

b SSF $\leq 205.80 \mathrm{~N}$.

c $205.80 \mathrm{~N}<\mathrm{SSF}<254.80 \mathrm{~N}$.

d SSF $\geq 254.80 \mathrm{~N}$.
The canonical discriminant procedure used in this study first determines the category (tender, intermediate, and tough) centers. Then it transforms the 40 original variables (textural features) into canonical variables with an objective to increase the distance between category centers and reduce the distance between each class center and samples of the same class. Therefore, it strives to achieve the most compact clusters, while each cluster is far apart from others. During this transformation, covariance matrices of size $40 \times 40$ have to be calculated for each class. The covariance matrices for tender, intermediate and tough classes were obtained from 94, 12 and 5 samples, respectively. Because of the less number of samples in intermediate and tough classes, the covariance matrices for these two classes may not be as accurate as that of tender class. Splitting of the dataset into training and validation will still reduce the number of intermediate and tough samples in the training set, and therefore yield inaccurate estimates of covariance matrices. In this situation, cross-validation is a valid statistical procedure to evaluate the model. Before industrial implementation, the model must be validated with new set of samples.

In the U.S. meat marketing system, beef products leave the packing plant at about 3 days post-mortem. It takes approximately 14 days for the beef products to reach the consumer. The beef industry needs an instrument that can scan fresh meat at 2-3 days post-mortem and predict ultimate 14day cooked-beef tenderness. Further work is needed to determine the relationship of scans made earlier post-mortem with the tenderness classification at 14-day post-mortem.

Any instrumentation that is meant for beef tenderness evaluation should be fast enough to keep up with a speed at which a beef carcass moves in a production line and should have the ability to be implemented on-line. The developed hyperspectral imaging system, an off-line system, took $10 \mathrm{~s}$ to acquire an image of a beef sample, and $10 \mathrm{~min}$ to assign a tenderness category. Hyperspectral images have redundant information about the object and often require application of dimensionality reduction methods such as PCA, to remove the redundant information. Such dimensionality reduction steps significantly increase the time required to process each image. In our data analysis, we used PCA as a dimensionality reduction method and identified eight important spectral bands or wavelengths. Implementing image processing routines at these selected bands would decrease the processing time significantly. Another use of these selected bands is to reduce image acquisition time by acquiring images at those selected wavelengths and such approach is called multispectral imaging. The developed hyperspectral imaging system was a pushbroom system that scans a line of the object and requires sequential object movement to build the whole hyperspectral image of the object. The principle at which the imaging system works makes it an off-line instrumentation. However, there are commercially available whiskbroom hyperspectral imaging system that does not require object movement. Fast and on-line beef tenderness evaluation instrumentation could be feasible with whiskbroom multispectral imaging systems.

GLCM, a spatial domain procedure, was employed to extract textural features from PC images. Du and Sun (2006) and Zheng et al. (2006) have evaluated both spatial and transformbased texture feature extraction procedures for tenderness prediction in cooked pork ham, and large, cooked beef joints, respectively. They suggested that features extracted from the 
transform-based methods such as wavelet, and Gabor, had better relationships with tenderness as compared to spatial features. Hence, other transform-based textural feature extraction procedures should be evaluated for hyperspectral images for beef tenderness prediction.

As a widely used multivariate dimensionality reduction technique, PCA was successfully implemented to remove redundant information from the hyperspectral images of beef samples. Bajwa et al. (2004) also implemented supervised (PCA and artificial neural network) and unsupervised (information entropy, first spectral derivative, and second spectral derivative) dimensionality reduction techniques, but concluded that the artificial neural network was application specific and it could outperform other methods. That is yet to be fully realized. Similarly, Lawrence et al. (2006) evaluated the partial least square regression approach for contaminant detection on poultry carcasses. Although PCA in this study provided good discrimination results, additional research is needed to compare and identify which dimensionality reduction technique works best for beef tenderness prediction.

\section{Summary and conclusions}

A hyperspectral imaging system with diffuse lighting was developed. Hyperspectral images $(n=111)$ of USDA Choice and Select beef longissimus steaks (14-day post-mortem) were collected. Principal component analysis and co-occurrence matrix analysis were implemented to extract features from the hyperspectral images. A discriminant model was developed using the extracted features. With a leave-one-out cross-validation procedure, the model predicted three tenderness categories - namely tender, intermediate, and tough - with an accuracy of $96.4 \%$.

Categorizing meat cuts by tenderness would enhance economic opportunities for cattle producers and processors by improving assessment of beef product quality to meet consumer expectations. Also, it would help the U.S. beef industry maintain or expand its market in the face of increasing competition from other protein sources. Labeling accurate quality factors on the packaging of retail cuts would add value to the products and benefit consumers.

\section{References}

Bajwa, S.G., Bajcsy, P., Groves, P., Tian L.F. 2004. Hyperspectral image data mining for band selection in agricultural applications. Transactions of the ASAE 47(3): 895-907.

Boleman, S.J., Boleman, S.L., Miller, R.K., Taylor, J.F., Cross, H.R., Wheeler, T.L., Koohmaraie, M., Shackelford, S.D., Miller, M.F., West, R.L., Johnson, D.D., Savell, J.W. 1997. Consumer evaluation of beef of known categories of tenderness. Journal of Animal Science 75(6): 1,521-1,524.

Boleman, S.L., Boleman, S.J., Morgan, W.W., Hale, D.S., Griffin, D.B., Savell, J.W., Ames, R.P., Smith, M.T., Tatum, J.D., Field, T.G., Smith, G.C., Gardner, B.A., Morgan, J.B., Northcutt, S.L., Dolezal, H.G., Gill, D.R., Ray, F.K. 1998. National Beef Quality Audit-1995: survey of producer-related defects and carcass quality and quantity attributes. Journal of Animal Science 76(1): 96-103.

Brooks, J.C., Belew, J.B., Griffin, D.B., Gwartney, B.L., Hale, D.S., Henning, W.R., Johnson, D.D., Morgan, J.B., Parrish Jr., F.C., Reagan, J.O., Savell, J.W. 2000. National Beef Tenderness Survey-1998. Journal of Animal Science 78(7): 1,852-1,860.
Cheng, X., Chen, Y.R., Tao, Y., Wang, C.Y., Kim, M.S., Lefcourt, A.M. 2004. A novel integrated PCA and FLD method on hyperspectral image feature extraction for cucumber chilling damage inspection. Transactions of the ASAE 47(4): 1,313-1,320.

Du, C.-J., Sun, D.-W. 2006. Correlating image texture features extracted by five different methods with the tenderness of cooked pork ham: a feasibility study. Transactions of the ASAE 49(2): $441-448$

Feuz, D.M., Umberger, W.J., Calkins, C.R., Sitz, B. 2004. U.S. consumers' willingness to pay for flavor and tenderness in steaks as determined with an experimental auction. Journal of Agriculture and Resource Economics 29(3): 501-516.

Haralick, R.M., Shanmugan, K., Dinstein, I. 1973. Textural features for image classification. IEEE Transactions Systems, Man, and Cybernetics SMC 3(6): 610-621.

Hildrum, K.I., Nilsen, B.N., Mielnik, M., Naes, T. 1994. Prediction of sensory characteristics of beef by near-infrared spectroscopy. Meat Science 38(1): 67-80.

Hildrum, K.I., Isaksson, T., Næs, T., Nilsen, B.N., Rødbotten, M., Lea, P. 1995. Near infrared reflectance spectroscopy in the prediction of sensory properties of beef. Journal of Near Infrared Spectroscopy 3: 81-87.

Jeremiah, L.E. 1996. The influence of subcutaneous fat thickness and marbling on beef: palatability and consumer acceptability. Food Research International 29(5-6): 513-520.

Jeyamkondan, S., Kranzler, G.A. 2003. Predicting beef tenderness using near-infrared spectroscopy. Presented at Photonics East, SPIE International Symposium, Providence, RI, October 27-31.

Johnson, R.A. 1998. Applied Multivariate Methods for Data Analysis. Duxbury Press, New York, NY.

Kim, M.S., Lefcourt, A.M., Chao, K., Chen, Y.R., Kim, I., Chan, D.E. 2002a. Multispectral detection of fecal contamination on apples based on hyperspectral imagery. Part I. Application of visible and near-infrared reflectance imaging. Transactions of the ASAE 45(6): 2,027-2,037.

Kim, M.S., Lefcourt, A.M., Chen, Y.R., Kim, I., Chan, D.E., Chao, K. 2002b. Multispectral detection of fecal contamination on apples based on hyperspectral imagery. Part II. Application of hyperspectral fluorescence imaging. Transactions of the ASAE 45(6): 2,039-2,047.

Kim, M.S., Chen, Y.R., Mehl, P.M. 2001. Hyperspectral reflectance and fluorescence imaging system for food quality and safety. Transactions of the ASAE 44(3): 721-729.

Koohmaraie, M. 1994. Muscle proteinases and meat aging. Meat Science 36: 93-104

Lawrence, K.C., Park, B., Windham, W.R., Mao, C. 2003. Calibration of a pushbroom hyperspectral imaging system for agricultural inspection. Transactions of the ASAE 46(2): 513-521.

Lawrence, K.C., Windham, W.R., Park, B., Heitschmidt, G.W., Smith, D.P., Feldner, P. 2006. Partial least squares regression of hyperspectral images for contaminant detection on poultry carcasses. Journal of Near Infrared Spectroscopy 14: 223-230.

Liu, Y., Lyon, B.G., Windham, W.R., Realini, C.E., Pringle, T.D.D., Duckett, S. 2003. Prediction of color, texture, and sensory characteristics of beef steaks by visible and near infrared reflectance spectroscopy: a feasibility study. Meat Science 65(3): 1,107-1,115.

Lorenzen, C.L., Hale, D.S., Griffin, D.B., Savell, J.W., Belk, K.E., Frederick, T.L., Miller, M.F., Montgomery, T.H., Smith, G.C. 1993. National Beef Quality Audit: survey of producer-related defects and carcass quality and quantity attributes. Journal of Animal Science 71(6): 1,495-1,502.

Lusk, J.L., Fox, J.A., Schroeder, T.C., Mintert, J., Koohmaraie, M. 2001. In-store valuation of steak tenderness. American Journal of Agricultural Economics 83(3): 539-550.

McKenna, D.R., Roebert, D.L., Bates, P.K., Schmidt, T.B., Hale, D.S., Griffin, D.B., Savell, J.W., Brooks, J.C., Morgan, J.B., Montgomery, T.H., Belk, K.E., Smith, G.C. 2002. National Beef Quality Audit-2000: survey of targeted cattle and carcass characteristics related to quality, quantity, and value of fed steers and heifers. Journal of Animal Science 80(5): 1,212-1,222. 
Mitsumoto, M., Maeda, S., Mitsuhashi, T., Ozawa, S. 1991. Nearinfrared spectroscopy determination of physical and chemical characteristics in beef cuts. Journal of Food Science 59(6): 1,493-1,496.

Morgan, J.B., Savell, J.W., Hale, D.S., Miller, R.K., Griffin, D.B., Cross, H.R., Shackelford, S.D. 1991. National beef tenderness survey. Journal of Animal Science 69(8): 3,274-3,283.

NAMP, 2007. The Meat Buyer's Guide. John Wiley \& Sons, New Jersey, NJ.

Park, B., Lawrence, K.C., Windham, W.R., Buhr, R.J. 2002. Hyperspectral imaging for detecting fecal and ingesta contaminants on poultry carcasses. Transactions of the ASAE 45(6): 2,017-2,026.

Park, B., Yoon, S.C., Lawrence, K.C., Windham, W.R. 2004. Hyperspectral image classification of fecal and ingesta identification by spectral angle mapper. Paper \# 04-3032. 2004 ASAE Annual Meeting, Ottowa, Ont., Canada.

Park, B., Windham, W.R., Lawrence K.C., Smith, D.P. 2005a. Dynamic thresholding method for improving contaminat detection accuracy with hyperspectral images. Paper \# 05-3071. 2005 ASAE Annual Meeting, Tampa, FL.

Park, B., Yoon, S.C., Lawrence, K.C., Windham W.R. 2005b. Dynamic thresholding method for improving contaminant detection accuracy with hyperspectral images. Paper \# 05-3071. 2005 ASAE Annual Meeting, Tampa, FL.

Park, B., Chen, Y.R., Hruschka, W.R., Shackelford, S.D., Koohmaraie, M. 1998. Near-infrared reflectance analysis for predicting beef longissimus tenderness. Journal of Animal Science 76(8): 2,115-2,120.
Park, B., Chen, Y.R., Hruschka, W.R., Shackelford, S.D., Koohmaraie, M. 2001. Principal component regression of near-infrared reflectance for beef tenderness prediction. Transactions of the ASAE 44(3): 609-615.

Rødbotten, R., Mevik, B.-H., Hildrum, K.I. 2001. Prediction and classification of tenderness in beef from non-invasive diode array detected NIR spectra. Journal of Near Infrared Spectroscopy 9: 199-210.

Shackelford, S.D., Wheeler, T.L., Koohmaraie, M. 1999. Tenderness classification of beef. II. Design and analysis of a system to measure beef longissimus shear force under commercial processing conditions. Journal of Animal Science 77(6): 1,474-1,481.

Shackelford, S.D., Wheeler, T.L., Meade, M.K., Reagan, J.O., Byrnes, B.L., Koohmaraie, M. 2001. Consumer impressions of tender select beef. Journal of Animal Science 79(10): 2,605-2,614.

Vote, D.J., Belk, K.E., Tatum, J.D., Scanga, J.A., Smith, G.C. 2003. Online prediction of beef tenderness using a computer vision system equipped with a BeefCam module. Journal of Animal Science 81(2): 457-465.

Wheeler, T.L., Cundiff, L.V., Koch, R.M. 1994. Effect of marbling degree on beef palatability in Bos taurus and Bos indicus cattle. Journal of Animal Science 72(12): 3,145-3,151.

Xia, J.J., Berg, E.P., Lee, J.W., Yao, G. 2006. Characterizing beef muscles with optical scattering and absorption coefficients in VIS-NIR region. Meat Science 75: 78-83.

Zheng, C., Sun, D.W., Zheng, L. 2006. Classification of tenderness of large cooked beef joints using wavelet and Gabor textural features. Transactions of the ASAE 49(5): 1,447-1,454. 